INTERNATIONAL JOURNAL OF RESEARCHES IN BIOSCIENCES, AGRICULTURE AND TECHNOLOGY (C) VISHWASHANTI MULTIPURPOSE SOCIETY (Global Peace Multipurpose Society) R. No. MH-659/13(N) www.ijrbat.in

\title{
A SIMULATION STUDY OF THE REMOVAL EFFICIENCY OF GRANULAR ACTIVATED CARBON ON CADMIUM.
}

\author{
S. R. Trivedi and R. U. Khope \\ Department of Chemistry, Shri Shivaji Science College, \\ Congress Nagar Nagpur-440012, Maharashtra, India \\ Email: trivs217@gmail.com
}

\begin{abstract}
:
Ubiquity of noxious metals in water, soil and air are the grave problems that are an expanding threat to the environment. Consequently, the removal of heavy metals is a technological challenge with respect to industrial and environmental application. Adsorption is one of the encouraging processes used to get rid of the heavy metal ions from aqueous solution. In the presented inquest, the adsorption capacity of Cadmium (II) from aqueous solutions was studied on different grades of granular activated carbon namely Filtrasorb (F-300) and (F-400). The adsorption capacity of GAC towards Cadmium in dilute aqueous solutions concurred with the Langmuir and Freundlich model. The maximum removal for F-400 was observed at constant temperature $25 \pm 1^{\circ} \mathrm{C}$ and at $\mathrm{pH}=6$. It is definite from the study that the granulated activated carbon holds distinct promise in the removal of metal ions from aqueous solutions.
\end{abstract}

Keywords: Granular activated carbon (GAC), Filtrasorb (F-300), (F-400), adsorption, Cd (II).

\section{INTRODUCTION:}

The discharge of populous hunk of depreciated waste water not only pollutes the rivers and lands, but also the ground water. Noxious metal like Cadmium and human waste products bear an anathema to aquatic life as well as to human health [1]. Almost the entire world's production of Cadmium is obtained as a by-product from the fumes and flue dusts of the smelters treating zinc, lead and copper-ores, or as a by-product in the refining of Zinc or manufacture of Zinc Sulfate, Zinc Chloride and certain other chemicals. Cadmium base bearing alloys are used in high speed internal combustion engines [2]. Cadmium finds use in a scopic range of application like manufacture of nickel cadmium batteries, in coating and plating (due to excellent corrosive resistance), in pigment industry, plastic and synthetic products and in the form of alloy. In India Cadmium is consumed in an assortment of industries like paint, glass and chemicals [3]. In nuclear reactors, Cadmium is hired to control the fissionable elements. Cadmium fumes or dust are poisonous, and workers engaged in Cadmiumusing works are to be protected from inhalation of these fumes [4]. The methods such as precipitation, electroplating, chemical coagulation, ion-exchange, reverse osmosis, membrane separation, electro kinetics and adsorption are used for removal of heavy metals from aqueous solution. Adsorption using activated carbon is highly effective and economic technique for the removal of heavy metals from waste water. [5-7] Activated carbon is a black solid substance analogous to granular or powdered charcoal. It is inordinately porous with a substantial surface area.

\section{METHOD AND MATERIAL:}

All adsorption systems were carried out in a batch work. Calgon Corporation Ltd Pittsburgh adsorbents such as Filtrasorb400 (F-400) and Filtrasorb300 (F-300) gifted by $\mathrm{M} / \mathrm{s}$ Calgon Carbon, USA were selected as an adsorbent. Desired size of Carbon particles were obtained by using sieve shaker $(16$ x $25 \mathrm{M} / \mathrm{s}$ Jayant Test Sieves, Mumbai) and collected in clean petri-dish for use. The sieved GAC particles were thoroughly washed several times with hot distilled water until clear liquid was obtained and then kept in a vacuum oven at a temperature of $105^{\circ} \mathrm{C}$ overnight. It was then cooled in a desiccators containing silica gel to ensure complete removal of moisture from the carbon. A stock solution of cadmium ion was prepared by dissolving requisite amount of $\mathrm{CdCl}_{2} \cdot \mathrm{H}_{2} \mathrm{O}$, (Loba Chemie) in distilled water. A series of solutions of $\mathrm{CdCl}_{2} \cdot \mathrm{H}_{2} \mathrm{O}$ were prepared by using stock solution of $0.0001 \mathrm{M}$ concentration. In all cases absorbance was measured at $520 \mathrm{~nm}$ using Chemito Spectrascan UV 2700 Double beam Spectrophotometer. Standard Beer's law curve was constructed spectrophotometrically using series of 
Cadmium solutions and treating with Dithizone, Potassium-sodium tartrate and $\mathrm{NaOH}$ [11]. The mathematical equation computed was used to estimate the residual concentration of Cadmium ions in solution [12]. All reagents used in the present work were of analytical grade. To carry out the adsorption of Cadmium ion, $200 \mathrm{ml}$ solution at a $\mathrm{pH}=6$ was stirred for $5 \mathrm{hrs}$. in reagent bottle of $300 \mathrm{ml}$ capacity at a constant temperature of $25 \pm$ $1^{\circ} \mathrm{C}$ each time with different weights of Granular activated carbon using a Teflon blade stirrer. The initial and final concentration of Cadmium ion in $\mathrm{mg} / \mathrm{lit}$ were estimated using Beer's Law. The experiments were repeated twice to ensure reproducible results.

\section{RESULTS AND DISCUSSION:}

The relation between amount adsorbed and concentration is known as the adsorption isotherm. The experimental data of adsorption of $\mathrm{Cd}^{2+}$ ion GAC were analyzed in the light of Langmuir and Freundlich isotherms. The adsorption isotherm describes the relationship between the liquid phase concentration and surface concentration of adsorbate at equilibrium, the amount of cadmium with GAC was estimated

using the equation

$$
q_{e}=\left(C_{0}-C e\right) \times \frac{V}{W}
$$

Where,

$\mathrm{q}_{\mathrm{e}}=$ Concentration of Cadmium ion on the GAC in $\mathrm{mg} / \mathrm{gm}$,

$\mathrm{C}_{\mathrm{o}}=$ Initial concentration of Cadmium ion in solution in $\mathrm{mg} / \mathrm{L}$,

$\mathrm{C}_{\mathrm{e}}=$ Final concentration of Cadmium ion in solution in $\mathrm{mg} / \mathrm{L}$,

$\mathrm{V}=$ Volume of solution in litres,

$\mathrm{W}=$ Different weight of GAC.

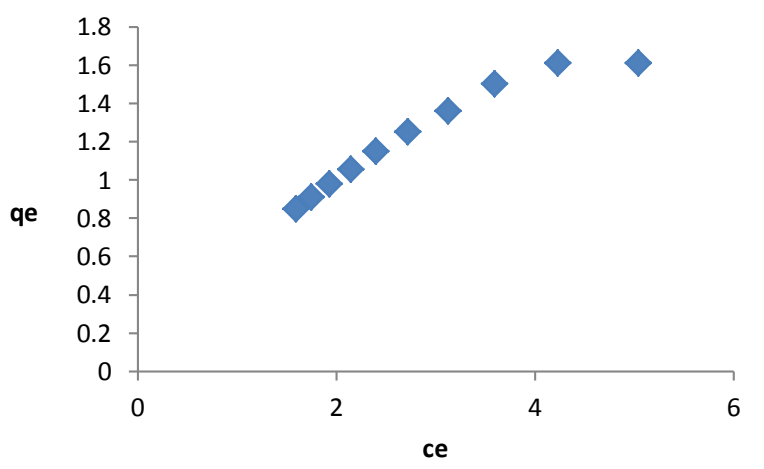

Fig.1. Adsorption Isotherm System: F-300_Cd2+

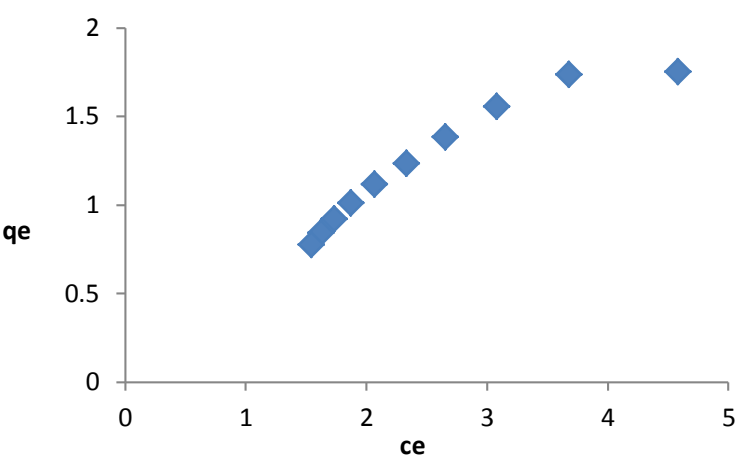

Fig.2. Adsorption isotherm System: F-400_Cd ${ }^{2+}$

The adsorption isotherms of F-300 and F-400 GAC obtained by plotting qe versus $\mathrm{C}_{\mathrm{e}}$ and shown in Fig. 1 and Fig. 2. The Langmuir equation could be expressed as

$$
\mathrm{q}_{\mathrm{e}}=\mathrm{Q}^{0} \mathrm{~b} \times \frac{\mathrm{C}_{\mathrm{e}}}{\left(1+\mathrm{bC}_{\mathrm{e}}\right)}
$$

Where,

$\mathrm{Q}^{\circ}=$ Amount adsorbed per unit weight of the adsorbent forming a monolayer on the adsorbent surface.

$\mathrm{b}=$ Empirical Langmuir constant.

Rearranging equation (2)

$$
\frac{1}{\mathrm{q}_{\mathrm{e}}}=\frac{1}{\mathrm{Q}^{0} \mathrm{~b}} \times \frac{1}{\mathrm{C}_{\mathrm{e}}}+\frac{1}{\mathrm{Q}^{0}}
$$

A plot of $1 /$ qeversus $1 / \mathrm{Ce}$ was found to be fairly linear. Similarly, the empirically derived Freundlich isotherm is defind as follows as

$$
\mathrm{qe}_{\mathrm{e}}=\mathrm{k} \cdot \mathrm{C}_{\mathrm{e}}^{1 / \mathrm{n}}
$$

Where, $\mathrm{k}=$ Empirical Freundlich constant or Capacity factor and

$1 / \mathrm{n}=$ Freundlich Exponent. Taking log of both sides,

$$
\log q_{e}=\log K+1 / n \log C_{e} \ldots \ldots
$$

A plot of $\log \mathrm{q}_{\mathrm{e}}$ versus $\log \mathrm{C}_{\mathrm{e}}$ fairly showing validity of Freundlich equation over a range of concentrations.

Fig. 3 to 6 illustrates the plots of Langmuir and Freundlich isotherms for F-300 and F-400. The plots of $1 / \mathrm{q}_{\mathrm{e}}$ versus $1 / \mathrm{C}_{\mathrm{e}}$ were found to be linear indicating the applicability of Langmuir model. The parameters $\mathrm{Q}^{\circ}$ and $\mathrm{b}$ are Langmuir constants relating to the sorption capacity and adsorption energy respectively were determined. 


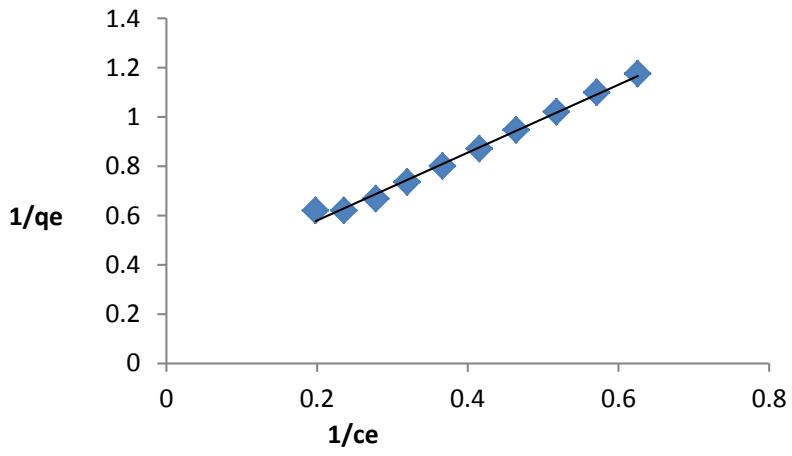

Fig.3 Langmuir adsorption isotherm System: F-300_Cd2+

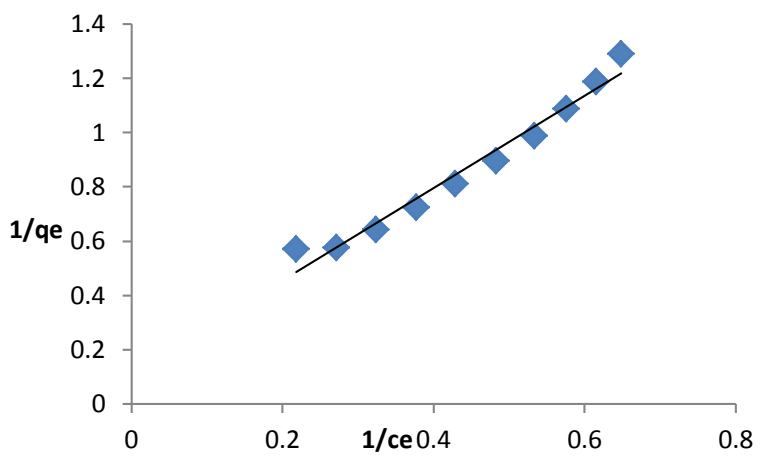

Fig. 4 Langmuir adsorption isotherm System: F-400_Cd ${ }^{2}$

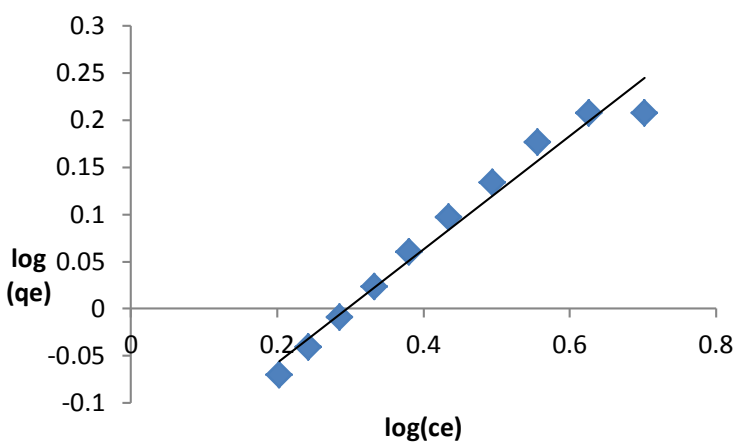

Fig. 5 Freundlich adsorption isotherm System: F-300_Cd2+

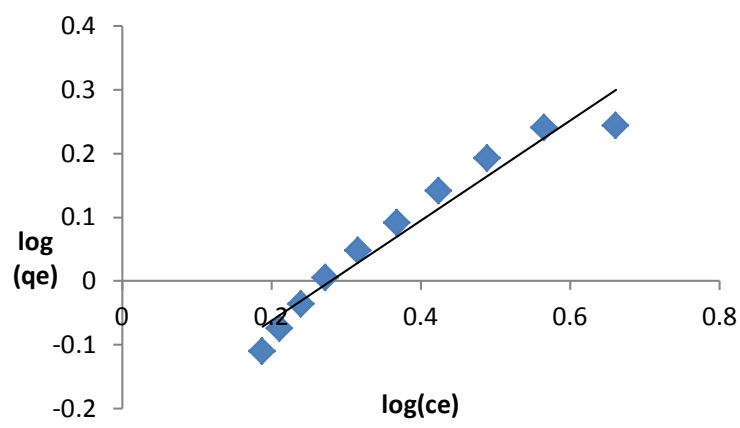

Fig. 6 Freundlich adsorption isotherm System: F-400_Cd²+
The plot of $1 / \mathrm{qeversus} 1 / \mathrm{C}_{\mathrm{e}}$ helped in determination of $\mathrm{Q}^{\circ}$ from which the surface area occupied by Cadmium ion on GAC can be determined. The surface area of the carbon through such Cadmium adsorption can then be represented as

$$
\mathbf{S}=\mathbf{N a} \mathbf{Q}^{\mathbf{O}} \mathbf{A}
$$

Where,

$\mathrm{S}=$ Surface area of adsorbent, $\mathrm{cm}^{2} / \mathrm{g}$,

$\mathrm{Na}=$ Avogadro number and

$\mathrm{A}=$ Cross-sectional area of the adsorbent

molecule, $\mathrm{cm}^{2}$.

It is possible to determine the surface area of the adsorbent using the technique of adsorbing Cadmium on GAC at the saturation level when a monolayer of the Cadmium would over the entire surface of the adsorbent. Determination of value of $S$ needed the determination of $A$ the surface area occupied by a single Cadmium ion. The values of A were calculated using the expression given bv ] $\mathrm{A}=4 \times 0.866\left[\frac{\mathrm{M}}{4 \sqrt{2} \cdot \mathrm{Na} \cdot \mathrm{d}}\right]^{2 / 3}$

Where,

$\mathrm{M}=$ Atomic weight of the Cadmium

$\mathrm{Na}=$ The Avogadro number

$\mathrm{d}=$ The density of the Cadmium

The values of $\mathrm{S}$ obtained from $\mathrm{q}_{\mathrm{e}}$ max obtained are reported in Table 1

\section{CONCLUSION:}

Adsorption by granular activated carbon is eco friendly, efficient and cost effective technique used for removal of heavy metal from wastewater. In this inquest, results showed that the adsorption of Cadmium ion performed by GAC was very encouraging. From the adsorption isotherm, it is observed that as $\mathrm{C}_{\mathrm{e}}$ increases $\mathrm{q}_{\mathrm{e}}$ also increases but at the saturation level qetends to be constant with increasing value of $\mathrm{C}_{\mathrm{e}}$ which indicates formation of a monolayer of Cadmium ion on the surface of adsorbent. Freundlich and Langmuir isotherm models described the adsorption data adequately. All adsorption isotherms of the Cadmium ion on different grades of carbons in presence of dithizone clearly show that F-400 adsorbs Cadmium ion to a greater proportion as compared to F-300. This is probably due to availability of large active sites on the surface of porous activated carbon. 


\section{ACKNOWLEDGEMENT:}

We express our sense of gratitude and thanks to the Principal, Shri Shivaji Science College, Congress Nagar, Nagpur for providing laboratory facilities to carry out the experimental work.

\section{REFERENCE:}

1. Agarwal K.M and SikdarP.K and Deb. S.C "A text book of environment", Macmillan India 1td first edition , 2002, p185.

2. Sharma N.L and Ram K.S.V "Introduction to India's Economic Minerals" first edition 1964 $\mathrm{p} 44$.

3. Indian Minerals Yearbook 2000, p278.

4. Natrajan G.S "Effectiveness of Activated Carbon for removal of metals from aqueous solution" Jr. of Industrial Pollution Control 22(1), (2006), p185-190.

5. Ali F, Mussa T, Abdulla A, Alwan A and Salih D "Removal of Cadmium from Wastewater using low cost Natural Adsorbents" Int Res J. Environment Sci Vol. 4(6), 2015, p11-15.

6. Ahluwalia V.K, Environmental Chemistry, Ane's Student Edition, 2008, p 186.

7. Dara S.S. 'A text book of environmental Chemistry and Pollution Control' S.Chand and Co. Ltd. New Delhi, 2002, 1, 215.

8. Mukharjee A.G., 'Environmental Pollution and Health Hazards: Causes and Control', S.Galgotia, New Delhi, 1986, p58.
9. Snell Dee Foster, Snell T Cornelia Van Nostr 10. and Reinhold, Company New York, p46

11.Benoit P, Barriuso E. and Caver R., Chemosphere, 1998, p37.

12.Vishnoi N. K., 'Advanced Practical Organic Chemistry', Vikas Publishing House Pvt. Ltd., 1979, Vol. 1, p194.

13.Vogel A. I., Quantitative Inorganic Analysis, 4th 14.Edition, Longman Group Ltd. England, 1978, p739.

15.Yen T. F, Prentice Hall PTR, Upper saddle River, 1999.

16.Kang S. Y., Lee J.U., Moon S.H., Kim K. W., Chemosphere, 2000, 56, 141.

17.Skinner J. H., Bassin N. J., The environment protection agency's hazardous waste research and development program., J. APCA, 1988.

18. Mahvi A. H., Int. J. Environ. Sci. Tech., 2008, 5(2), 275.

19. Malakootian M., Almasi A., Hossaini H., Int. J. Environ. Sci. Tech., 2009, 5(2),

20.Abbasi W. A. and M. Streat, Sep. Sci. Technol., 1994, 29, 1217

21.Kirk-Orthmer, Encyclopedia of Chemical Technology, Wiley-Interscience, USA, 1997, 24, Fourth Ed.

22. WHO (World Health Organization), 2nd ed., vol1, p 188(1993)

Table. 1- Values of $\mathrm{Q}^{\circ}, \mathrm{A}$ and $\mathrm{S}$ for a system $\mathrm{GAC}-\mathrm{Cd}^{2+}$

\begin{tabular}{|c|c|c|c|c|c|}
\hline Sr. No. & System & $\mathbf{Q}^{\mathbf{0}}$ & $\begin{array}{c}\mathbf{A} \\
\mathbf{( c m}^{\mathbf{2}} \mathbf{)}\end{array}$ & $\mathbf{S} \mathbf{( c m}^{\mathbf{2}} \mathbf{\text { gmm } )}$ & $\mathbf{q}_{\operatorname{emax}}$ (mg/gm.) \\
\hline 1 & $\mathrm{~F}-300-\mathrm{Cd}^{2+}$ & 3.2829 & $8.4563 \times 10^{-16}$ & $7.2997 \times 10^{3}$ & 1.6111 \\
\hline 2 & $\mathrm{~F}-400-\mathrm{Cd}^{2+}$ & 8.5910 & $8.4563 \times 10^{-16}$ & $7.9291 \times 10^{3}$ & 1.7500 \\
\hline
\end{tabular}

Table. 2- Values of Langmuir adsorption isotherm constant and Freundlich adsorption isotherm constant.

\begin{tabular}{|c|c|c|c|c|c|c|c|}
\cline { 3 - 8 } \multicolumn{2}{c|}{} & \multicolumn{3}{c|}{$\begin{array}{c}\text { Value of Langmuir } \\
\text { constant }\end{array}$} & \multicolumn{3}{c|}{$\begin{array}{c}\text { Value of Freundlich } \\
\text { constant }\end{array}$} \\
\hline Sr. No. & System & $\mathrm{Q}^{0}$ & $\mathrm{~b}\left(\mathrm{~cm}^{2}\right)$ & $\mathrm{R}^{2}$ & $\mathrm{~K}$ & $1 / \mathrm{n}$ & $\mathrm{R}^{2}$ \\
\hline 1 & $\mathrm{~F}-300-\mathrm{Cd}^{2+}$ & 3.2829 & 0.2208 & 0.9923 & 0.6645 & 0.6005 & 0.9719 \\
\hline 2 & $\mathrm{~F}-400-\mathrm{Cd}^{2+}$ & 8.5910 & 0.6851 & 0.9684 & 0.6032 & 0.7852 & 0.9474 \\
\hline
\end{tabular}

